\title{
Development of Nanosilicate-Hydrogel Composites for Sustained Delivery of Charged Biopharmaceutics
}

\author{
Samuel T. Stealey ${ }^{l}$,Akhilesh K. Gaharwar ${ }^{2}$, Nicola Pozzi ${ }^{3}$, Silviya Petrova Zustiak ${ }^{1, *}$
}

${ }^{1}$ Biomedical Engineering Program, School of Engineering, Saint Louis University, Saint Louis, MO, USA 63103, ${ }^{2}$ Biomedical Engineering, Dwight Look College of Engineering, Texas A\&M University, College Station, TX, USA 77843, ${ }^{3}$ Department of Biochemistry and Molecular Biology, Saint Louis University School of Medicine, Saint Louis, MO, USA 63103

\section{* Corresponding Author}

Silviya Petrova Zustiak

Program of Biomedical Engineering

School of Engineering

Saint Louis University

Saint Louis, MO, USA, 63103

Tel: $314-977-8331$

Fax: 314-977-8403

E-mail: silviya.zustiak@slu.edu 


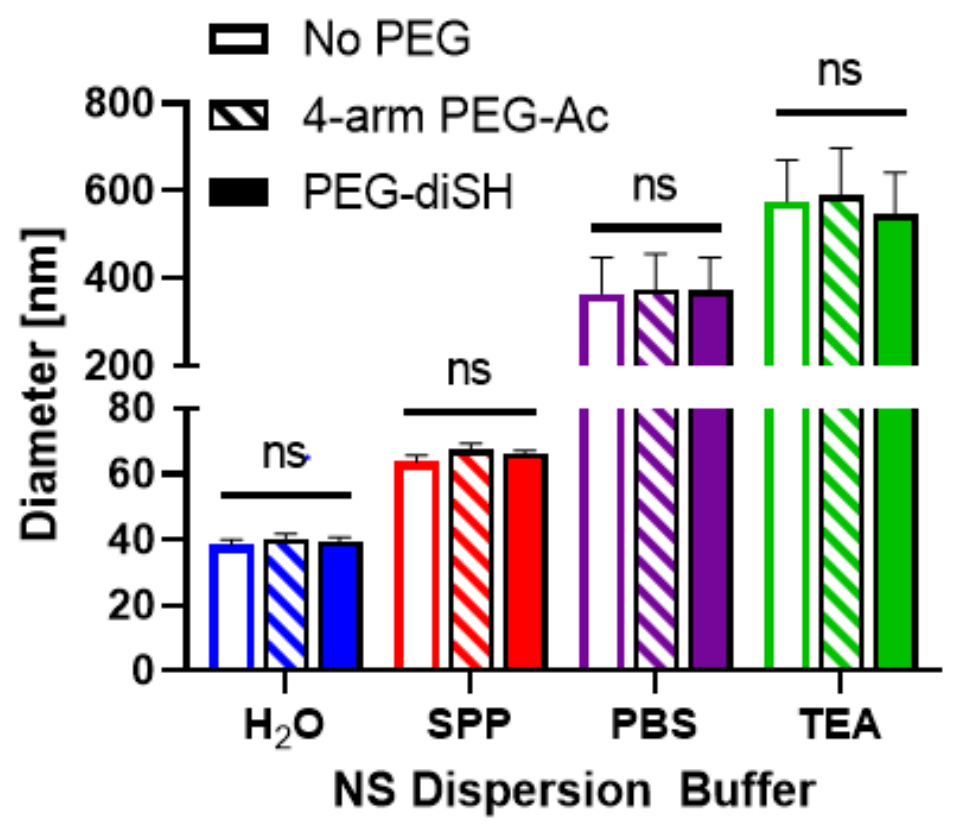

Figure S1: Incubation with PEG polymer did not affect NS particle size, indicating no NS-

PEG interaction. NS $(0.5 \mathrm{mg} / \mathrm{mL})$ dispersed in $\mathrm{H}_{2} \mathrm{O}$ or SPP was incubated in buffer only or with 4-arm PEG-Ac and PEG-di-SH $(0.1 \mathrm{mg} / \mathrm{mL})$ for 30 min prior to DLS measurements of particle size. No significant difference was found between conditions $(\mathrm{N}=3, p<0.05)$. 

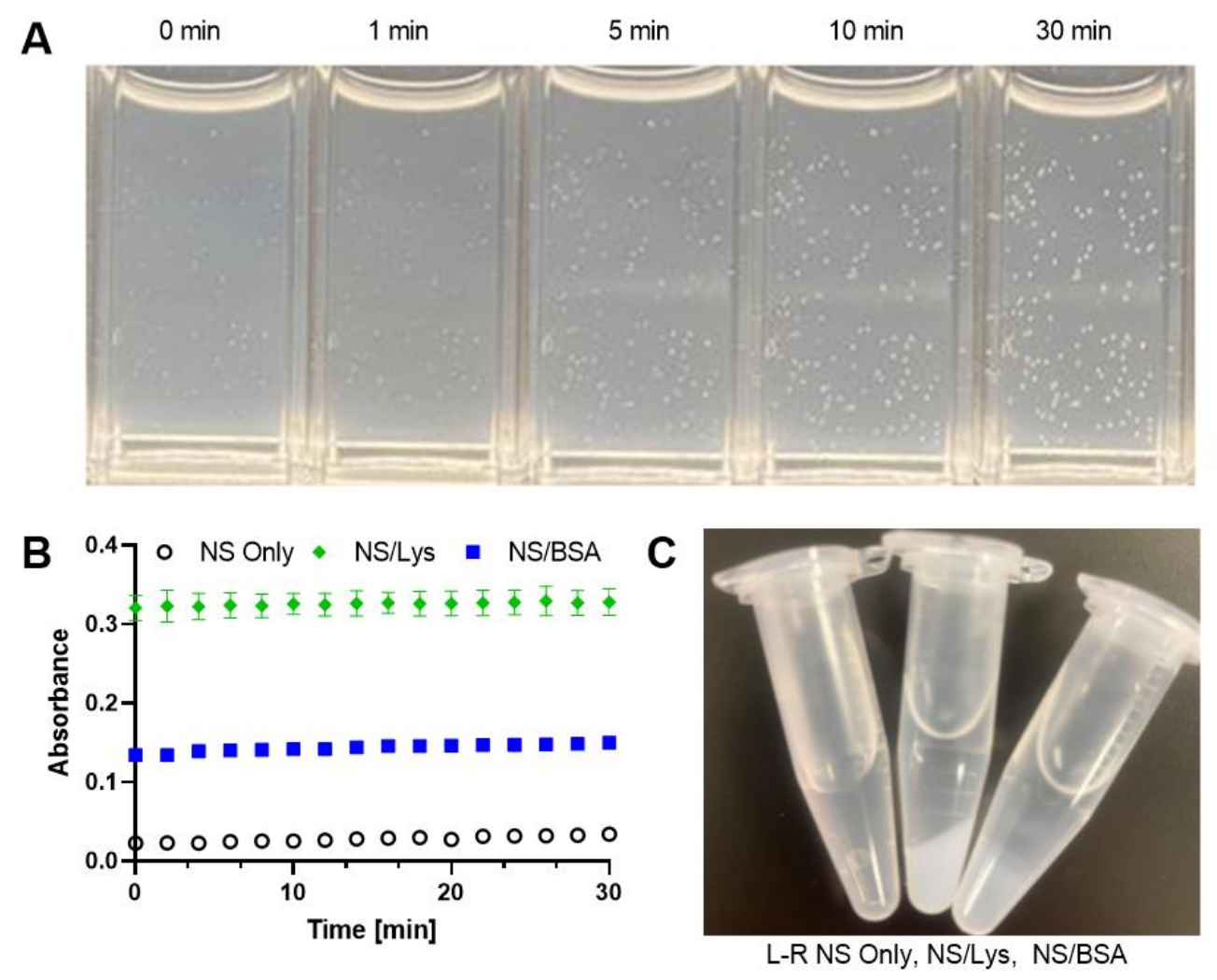

Figure S2: Sedimentation of NS and NS-Protein complexes. A. Images of $1 \mathrm{mg} / \mathrm{mL}$ NS mixed with $10 \mathrm{mg} / \mathrm{mL}$ Lys at different time points. Images were taken without any agitation of the solution between time points. B. Absorbance at $\lambda=500 \mathrm{~nm}$ of NS Only $(10 \mathrm{mg} / \mathrm{mL}), 1 \mathrm{mg} / \mathrm{mL}$ NS and $1 \mathrm{mg} / \mathrm{mL}$ Lys, and $1 \mathrm{mg} / \mathrm{mL}$ NS and $1 \mathrm{mg} / \mathrm{mL}$ BSA following $30 \mathrm{~min}$ of incubation and gentle shaking prior to measurements. C. Sedimentation following 2 min of centrifugation at 10,000 RPM of NS Only, NS/Lys and NS/BSA. No pellet was visible for NS only but was apparent for both NS/BSA and NS/Lys. 
$\square$ No PEG $\boldsymbol{\nabla}$ 4-arm PEG-Ac ■ PEG-diSH

$\mathrm{H}_{2} \mathrm{O}$
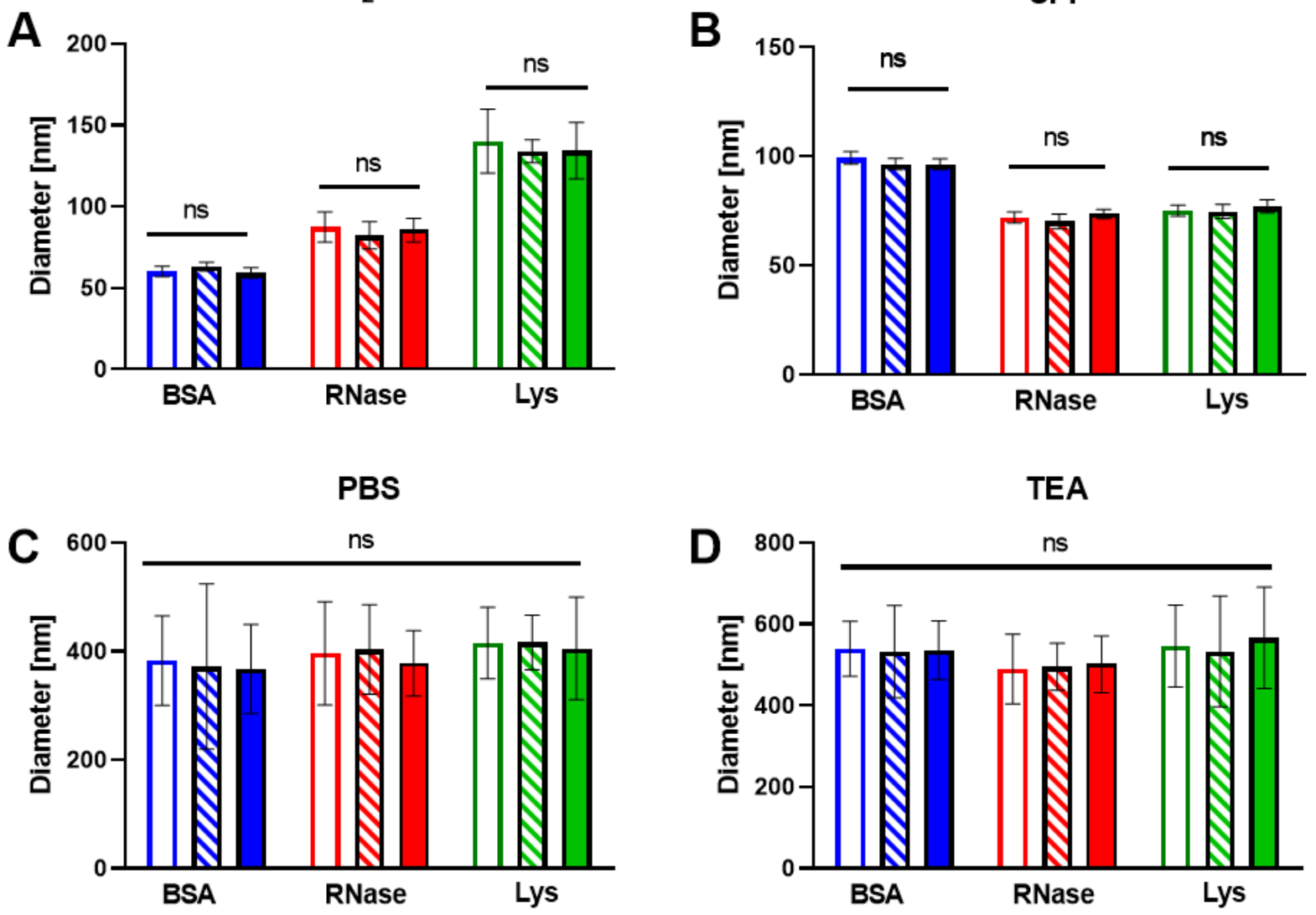

Figure S3: PEG polymer did not interfere with NS-protein complex formation. NS (0.5 $\mathrm{mg} / \mathrm{mL})$ and 4-arm PEG-Ac $(0.1 \mathrm{mg} / \mathrm{mL})$ or PEG-diSH $(0.1 \mathrm{mg} / \mathrm{mL})$ were incubated for $30 \mathrm{~min}$ first and then both were incubated with BSA, RNase or Lys $(0.1 \mathrm{mg} / \mathrm{mL})$ for 30 min prior to DLS measurements. No significant difference was found between conditions $(\mathrm{N}=3, p<0.05)$. 


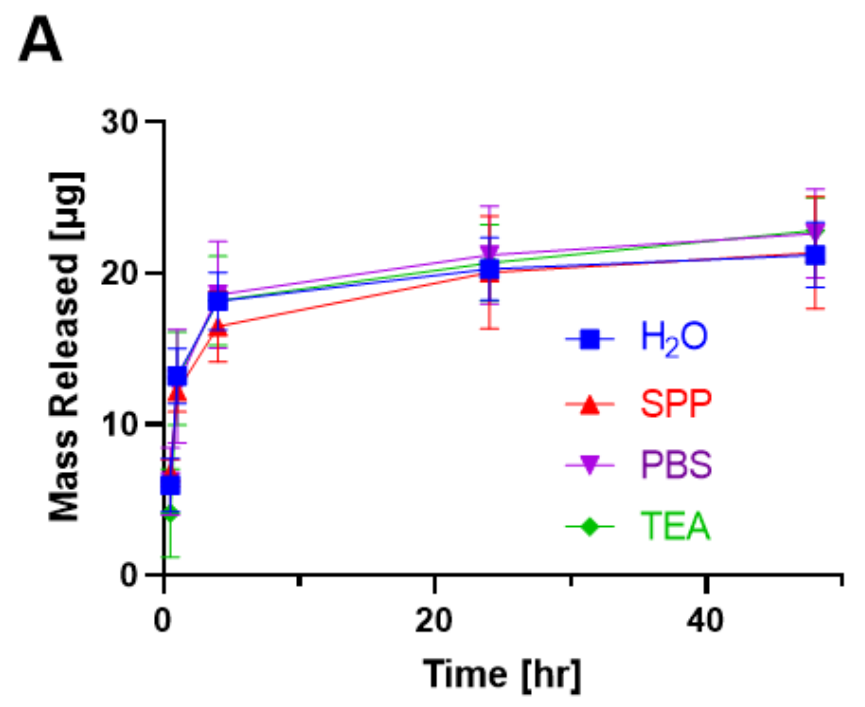

B

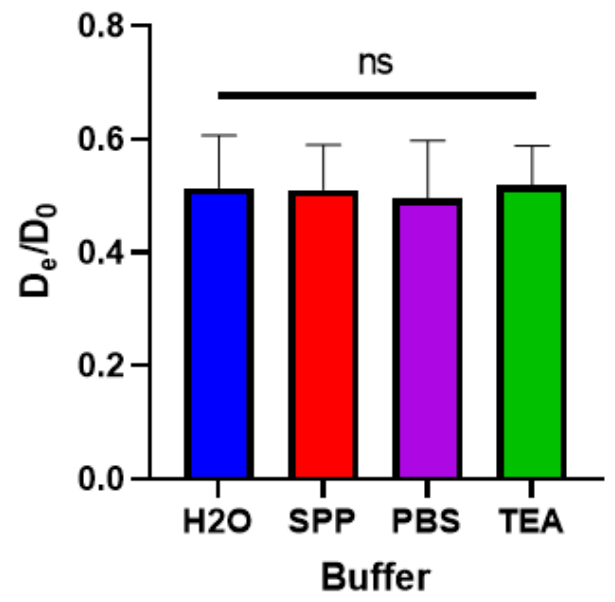

Figure S4: The dispersion buffer did not affect protein release from PEG hydrogels in the absence of NS. Effect of dispersion buffer on Lys $(1 \mathrm{mg} / \mathrm{mL})$ release $(\mathbf{A})$ and diffusivity (B) from PEG Only hydrogels (no NS). No significant difference was found between conditions $(\mathrm{N}=3, p$ $<0.05)$. 


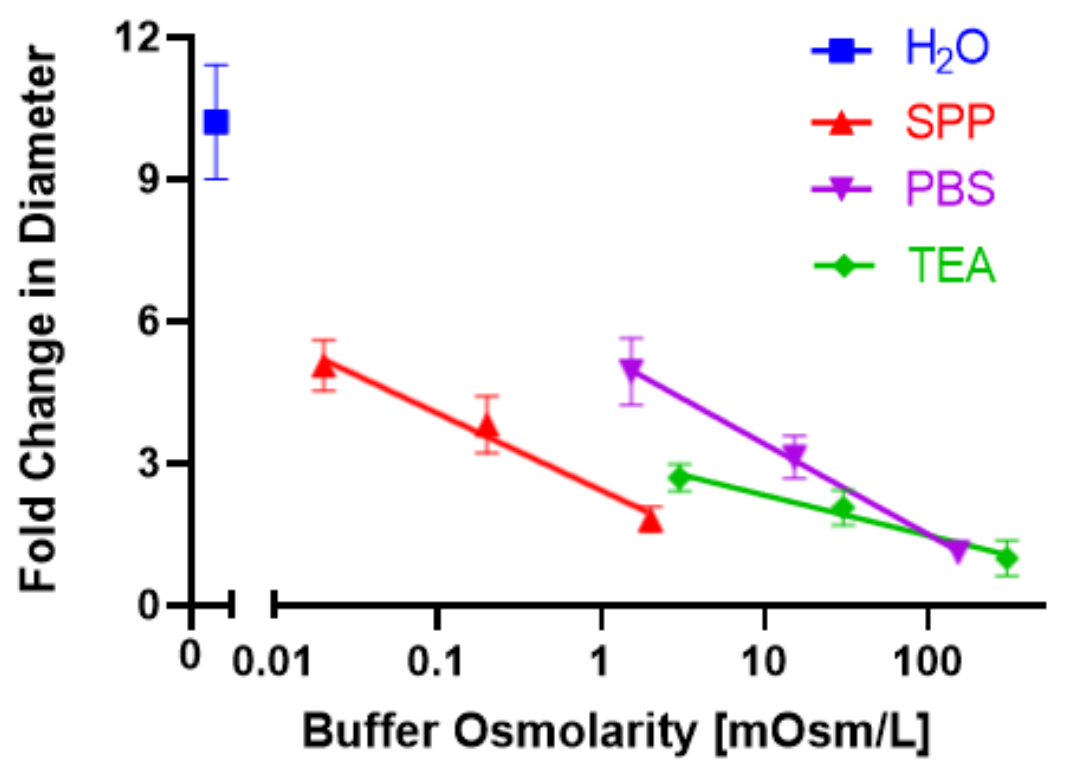

Figure S5: DLS with changing buffer concentrations. Dilutions of $1 / 10$ and $1 / 100$ of each buffer were prepared by adding appropriate amount of DI water. NS $(2 \mathrm{mg} / \mathrm{mL})$ and Lys $(0.05 \mathrm{mg} / \mathrm{mL})$ were then added to observe effect of buffer ionic strength (osmolarity) on complex formation. * indicates significant difference between all buffer concentrations for specified buffer $(\mathrm{N}=5$ and $p$ $<0.05)$ 

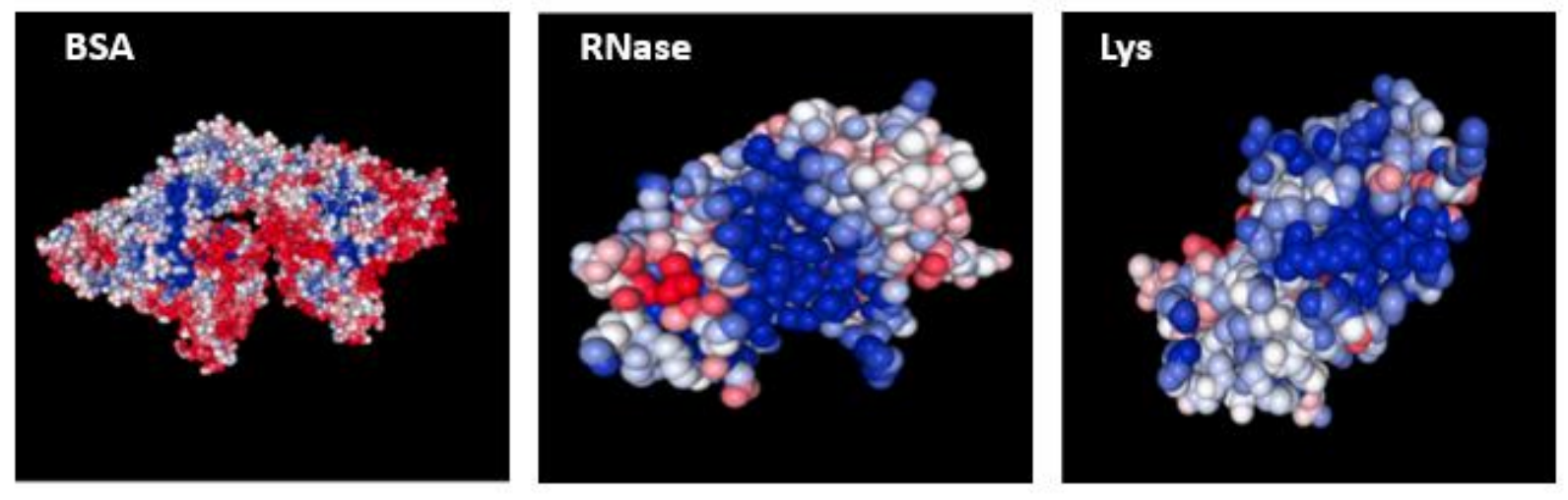

Figure S6: Anisotropic surface charge of proteins is shown by highlighting acidic amino acid residues in red (negative charge) and basic amino acid residues in blue (positive charge). 

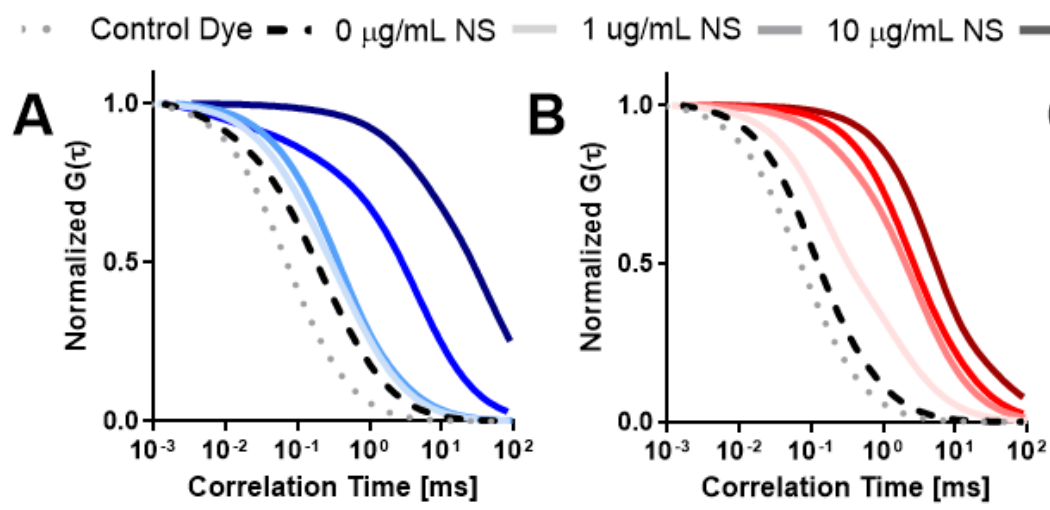

$100 \mu \mathrm{g} / \mathrm{mL} \mathrm{NS}-1000 \mu \mathrm{g} / \mathrm{mL} \mathrm{NS}$

Figure S7: Representative normalized autocorrelation functions of $1 \mu \mathrm{g} / \mathrm{mL}$ BSA (A), RNase (B), and Lys (C) with varying concentrations of NS measured via fluorescence correlation spectroscopy. 

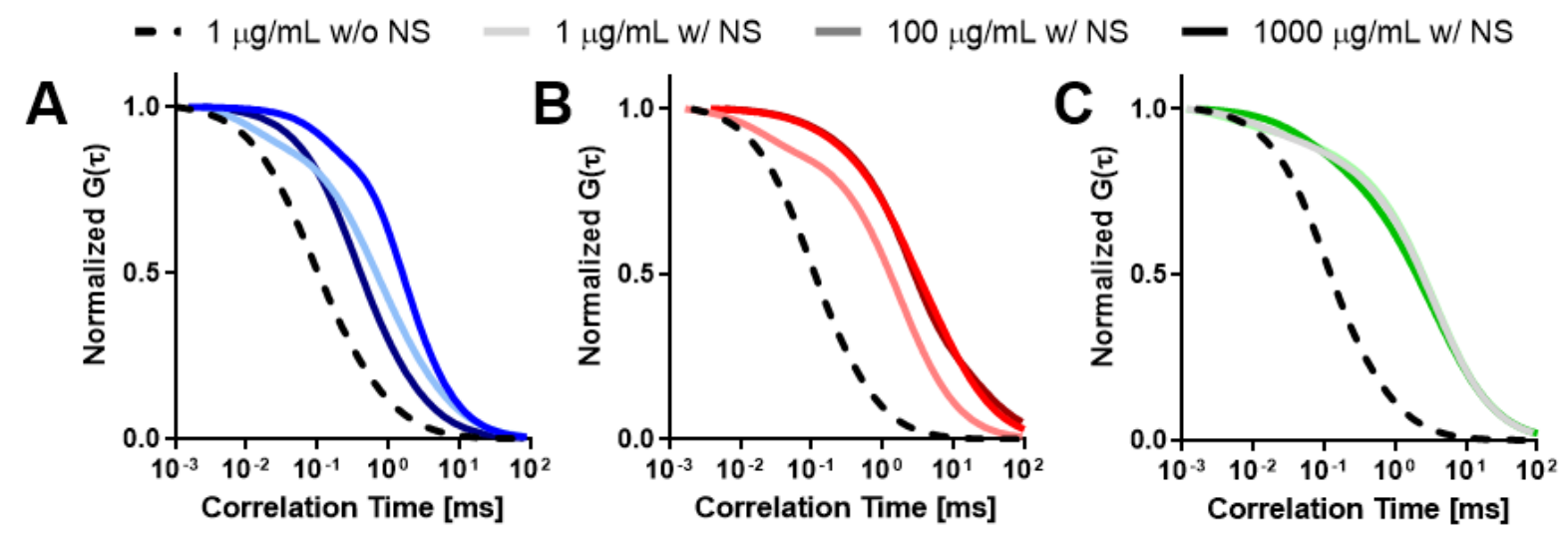

Figure S8: Representative normalized autocorrelation functions of varying concentrations of BSA (A), RNase (B), and Lys (C) with $10 \mu \mathrm{g} / \mathrm{mL}$ of NS measured via fluorescence correlation spectroscopy. 


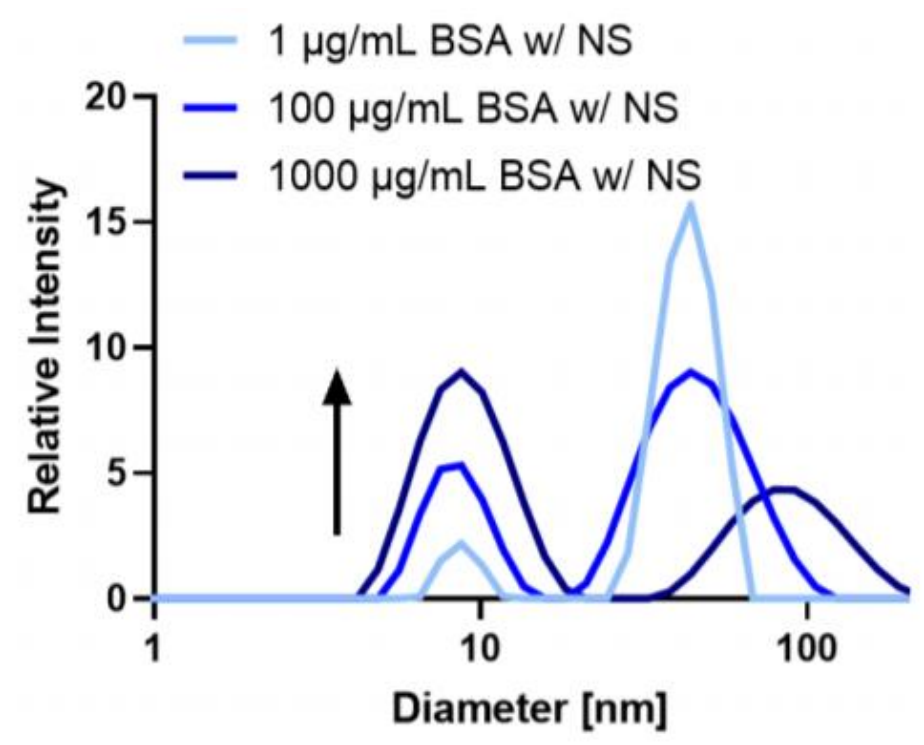

Figure S9: Oligomerization of BSA at High Protein Concentration. Raw DLS relative intensity values for 1,100 and $1000 \mu \mathrm{g} / \mathrm{mL}$ BSA with $10 \mu \mathrm{g} / \mathrm{mL}$ NS. As can be seen by the relative height of the peaks, BSA-BSA interactions ( $\sim 9 \mathrm{~nm}$ in diameter) seem to be more prevalent than that of NS-BSA complexes $(\sim 100 \mathrm{~nm}$ in diameter) as protein concentration increased. Alternatively, there is a possibility the DLS curves may represent a bimodal deconvolution of a very broad distribution of NS-BSA complex sizes. 


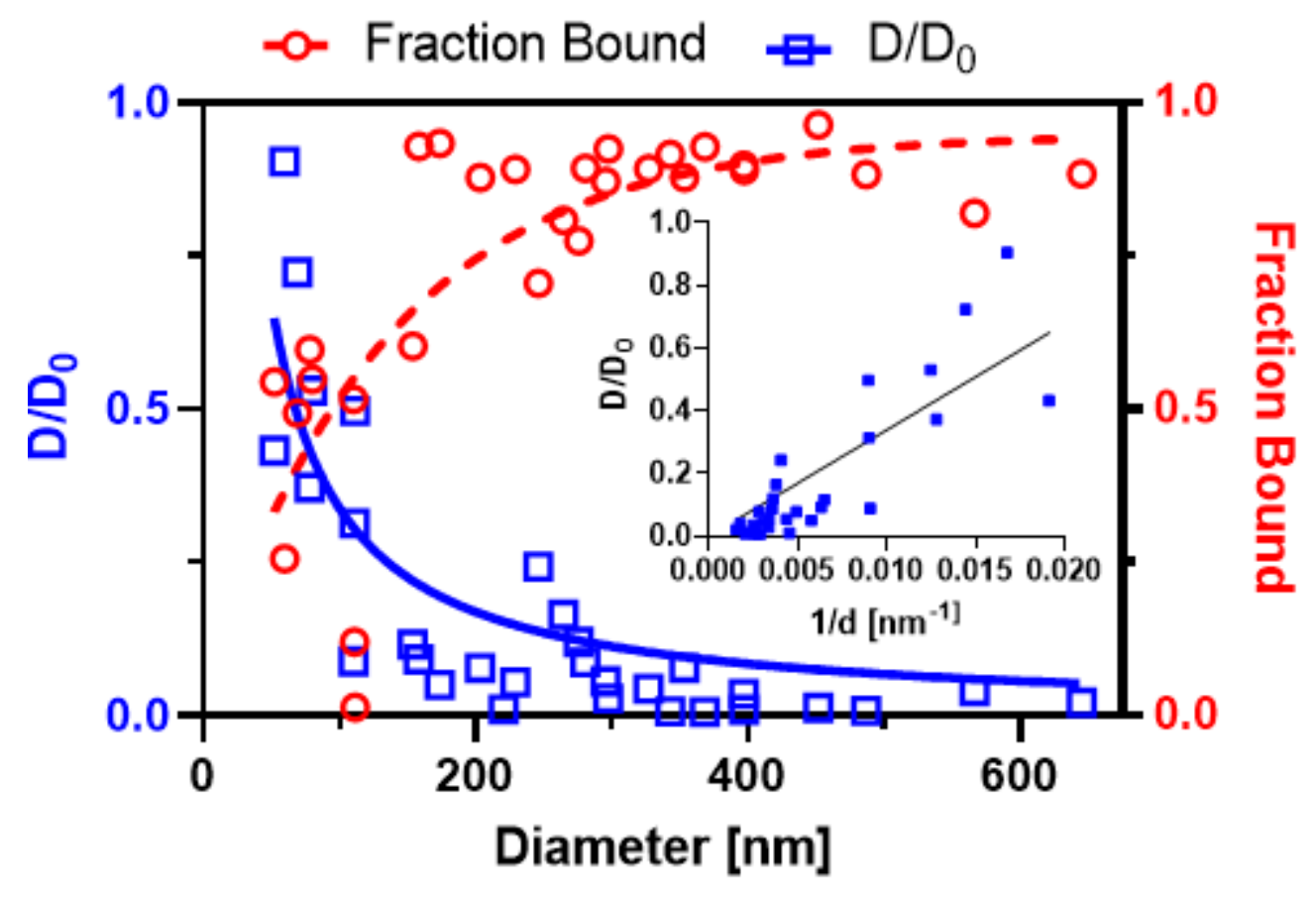

Figure S10: Effect of NS-protein complex diameter on complex diffusivity and protein bound

fraction. Measurements were performed with FCS (see Figure 6 and 7 in main text). Trendlines are simple inverse functions and were fitted using GraphPad Prism software's Inverse Function with $\mathrm{R}^{2}=0.81$ for $\mathrm{D} / \mathrm{D} 0$ and $\mathrm{R}^{2}=0.70$ for Fraction Bound. Inset: Plot of D/D0 versus 1/diameter, showing inverse relationship $\left(\mathrm{R}^{2}=0.81\right)$. 